\title{
Do Plano à Política de saúde no sistema \\ prisional: diferenciais, avanços, limites e desafios
}

SILVA, Martinho.

Saúde penitenciária no Brasil: plano e política.

Brasília: Verbena, 2015. 117p.

| ${ }^{1}$ Reni Barsaglini I

1 Instituto de Saúde Coletiva, Universidade Federal do Mato Grosso. Cuiabá-MT, Brasil (barsaglinireni@gmail.com).

As questôes relacionadas à população privada de liberdade são ainda escassas nas pesquisas e publicações na área de saúde e, especificamente, na Saúde Coletiva. Entre os parcos estudos, sobressaem os quantitativos, como mostra recente revisão sobre o tema (GOIS et al., 2012), fato que ofusca a própria existência e situação deste grupo social no contexto das políticas públicas e compromete a universalidade, a integralidade e equidade da atenção propostos, no âmbito do Sistema Único de Saúde (SUS).

Nesse cenário é que a obra assinada por Martinho Silva é muito bem-vinda, preenchendo considerável lacuna. Comprometido com o direito à saúde, o autor nos fala, de uma perspectiva de pesquisador desde 2008, das políticas públicas voltadas à saúde mental de modo geral e, particularmente, àquela dirigida à população em cumprimento de medida de segurança (e não pena punitiva de privação de liberdade) em hospitais de custódia e tratamento. $\mathrm{O}$ autor assessorou a Área Técnica de Saúde no Sistema Penitenciário (SISPE), do Ministério da Saúde (MS) em relação à legislação da saúde no sistema penitenciário sintetizada em publicação oficial (BRASIL, 2010).

Lembramos que a saúde no sistema prisional consistia de ações pontuais e contou com um diferencial a partir da Lei de Execução Penal - LEP, no 7.210, de 1984 e, em um contexto de democratização, a Constituição Federal de 1988 
assumiu a saúde como dever do Estado e direito de todo cidadão, incluindose aquele em privação de liberdade. A proposição do SUS incluía a saúde da população do sistema prisional pelo princípio da universalidade, mas ainda timidamente. Significativo impulso adveio de sua institucionalização, ao ser focalizada pelas publicações das Portarias Interministeriais (Saúde e Justiça) no 668/2002 (revogada, conforme o autor explica) e no 1.777/2003, que instituíram o Plano Nacional de Saúde no Sistema Penitenciário (PNSSP), vigente de 2002 a 2013 e, recentemente, pela Política Nacional de Atenção Integral à Saúde das Pessoas Privadas de Liberdade no Sistema Prisional (PNAISP), em 2014.

Assim é que a presente obra é fruto da pesquisa intitulada "Do Plano à Política: garantindo o direito à saúde para todas as pessoas do sistema prisional", desenvolvida entre 2011 e 2013, no Programa de Direito Sanitário da Diretoria Regional de Brasília da Fundação Oswaldo Cruz (PRODISA - Fiocruz Brasília), que foi coordenada pelo autor e financiada pelo Fundo Nacional de Saúde. Tratase de uma ação conjunta da Área Técnica de Saúde no Sistema Penitenciário do Departamento de Ações Programáticas e Estratégicas na Secretaria de Atenção à Saúde/Ministério da Saúde e do Departamento Penitenciário Nacional/ Ministério da Justiça.

A concepção desta pesquisa avaliativa visava, justamente, contribuir para o processo decisório da gestão federal dos Ministérios envolvidos, subsidiando a transição entre o PNSSP em vigor desde 2002, e a PNAISP, que passou a vigorar a partir de 2014. Se o objetivo era a elaboração de uma política pública para a população carcerária e não apenas a penitenciária (que veio a ser a PNAISP, doravante referida como Política), ela se faria a partir da avaliação da intervenção em curso (que era o Plano propriamente) levantando os pontos positivos, mas também os entraves, obstáculos que foram tomados como promotores de aprendizagem para aprimoramentos na tomada de decisão na (re)formulação da intervenção em curso. Entende-se tratar de uma avaliação de implementação (de política), esta considerada não como etapa autônoma e subsequente à formulação, nem limitada a um instrumento de "correção de rota”, mas momento em que pode subsidiar constantes reformulações, ajustes, rearranjos e redirecionamentos enriquecidos por um processo de aprendizagem policy learning (SILVA; MELO, 2000), seja pessoal ou institucional, favorecendo o aprimoramento da própria intervenção. 
É a dimensão pedagógica da avaliação de implementação que amplia sua função de contribuir com a prática cotidiana de gestão na tomada de decisão, pressupondo que não há uma relação direta e linear entre esses termos (avaliação/ tomada de decisōes), mas ambos operam juntos por razões que vão além das evidências técnicas, o custo e a efetividade (MARTINIC, 1997) envolvidos no processo decisório. No contexto da tensão entre as racionalidades técnica e política, inerentes à complexidade que envolve essa iniciativa no âmbito das intervenções sociais, a avaliação pode participar na formação do juízo, dos critérios ou da argumentação que sustentam uma decisão (DUARTE et al., 2012).

$\mathrm{O}$ objeto da pesquisa é coberto por Martinho em três fases, iniciando por uma descrição documental do PNSSP; quatro momentos de reuniôes/ encontros com variados segmentos interessados na avaliação (envolvidos com o atendimento de pessoas privadas de liberdade, como gestores, trabalhadores, familiares, pesquisadores, egressos do sistema prisional) para recolher propostas à formulação da Política; sistematização deste material em forma de princípios, diretrizes, responsabilidades de cada ente, financiamento e outros elementos constitutivos de uma política pública. Este conteúdo é apresentado ao longo do livro, que foi organizado em quatro partes, sendo a primeira constituída da Introdução, em que discorre sobre a originalidade da pesquisa avaliativa proposta e explicita seus aspectos teóricos e metodológicos.

Ressalta-se o cuidado em proporcionar ambientes inclusivos de debates com chances de disparar vetores de reflexividade, engajamento e implicação entre os participantes, dando voz a outros atores sociais, e não só gestores. A intenção foi produzir de maneira participativa os critérios de avaliação, apresentando juízos de valor sobre a eficácia da ação governamental em curso (o Plano), inclusive envolvendo seus beneficiários (próprios usuários do SUS egressos do sistema prisional) para que a Política não viesse a reproduzir as mesmas limitações e dificuldades no acesso. Trata-se do que Patton (2005) argumentou como sendo a chave para que os resultados de uma avaliação sejam úteis: o envolvimento dos agentes que se mostram dispostos a aprender com ela (a quem importa?) e que são os potenciais usuários de uma avaliação responsável.

Na segunda parte, intitulada Plano Nacional no Sistema Penitenciário (20022013): uma análise no contexto da implantação do Sistema Único de Saúde, é apresentada uma análise do Plano no contexto da implantação do SUS e os 
diferenciais da Política em formulação. Chama a atenção para o fato de as críticas e limitações ao Plano ofuscarem seu caráter avançado, se tomado em relação ao que estava previsto sobre saúde na LEP/1984 e o que ele fez nos 12 anos de operação. Tais avanços se respaldaram nos aparatos legais, como a Constituição Federal/1988, a Lei no 8.080/1990, a Norma Operacional de Assistência à Saúde (NOAS/2002), quanto à provisão da atenção integral à saúde (prevenção, promoção, assistência), sendo que a Política como diferencial (sucessora do Plano), se orientaria pelas Redes de Atenção em Saúde (RAS/2011).

$\mathrm{O}$ autor entende que o Plano se coaduna com a universalidade do acesso aos demais níveis de atenção à saúde, ou seja, o especializado e não apenas o da atenção básica, contudo o foco era na redução de riscos, prevenção de agravos e doenças. Aponta a limitação dos dois indicadores normativos de avaliação previstos no próprio Plano quanto ao seu objetivo de prover atenção integral à saúde da população prisional (grifo no original), que são o quantitativo de estados da federação qualificados ao Plano e de Equipes de Saúde no Sistema Penitenciário (EPENs) instaladas em estabelecimentos penais. Segundo tais indicadores, o Plano, em dez anos, seria muito bem-sucedido, ainda que deixasse a desejar pelo número de EPENs cuja cobertura da assistência seria de 25 a 30\% da população. Passa a considerar, então, outros elementos na avaliação do Plano como o contraste da cobertura assistencial de outros programas governamentais. Um deles seria a Estratégia de Saúde da Família (ESF), mostrando aumento, mas também a desproporcionalidade em relação ao crescimento da população carcerária e da população em geral/nacional. Outro é o da área de saúde mental quanto ao número de Centros de Apoio Psicossocial (CAPS) implantados, cujas ações e serviços dirigem-se a uma população específica e apresenta aumento nos últimos anos e, portanto, incremento do acesso. Em ambos os casos, no entanto, se considerar o tempo isoladamente para as respectivas coberturas, o Plano seria também um sucesso.

Após explicar os procedimentos de adesão dos Estados ao Plano com a assinatura de Termo de Adesão e formulação do Plano Operativo Estadual, traz dados que relativizam o discurso pessimista sobre o Plano, indicando diferenciais que constituiriam avanços quando comparado à LEP que regia anteriormente as ações de saúde, por exemplo, ela citava "assistência" ao "presos", e o Plano alude à "atenção integral” à "população prisional”, ainda que recorte a população 
penitenciária. Da mesma forma, a LEP cita vagamente a prevenção, mas não a prioriza, enquanto o Plano a enfatiza e inclui a promoção da saúde, ainda que se constitua como "algo mais apropriado para fazer frente à insalubridade e superpopulação no sistema prisional” (p. 33). Da mesma forma, na LEP a ação dos psicólogos e assistentes sociais limitava-se mais a perícia e exames criminológicos, e o Plano prevê de forma mais incisiva, a inclusão dessas ações na área de saúde pelo trabalho em equipe.

Há, ainda, os diferenciais entre a Portaria no 668/2002 revogada, mas que instituía inicialmente o Plano antes da Portaria no 1777/2003: um deles se referia ao financiamento cujo incentivo seria per capita e não por equipe, embora tenha permanecido esta última devido à resistência por parte do Poder Legislativo justificando que seria maior do que para a população brasileira de modo geral, ainda que sabedor de que o custo da escolta era o item onerador. Outro se referia à cobertura assistencial em que, a primeira/revogada, estabelecia metas paulatinas e não o regular "100\%”. Por fim, a Saúde Mental estava contemplada na Portaria no 668/2002, em atividades quanto ao "diagnóstico e tratamento dos agravos à saúde mental dos internos" e "desenvolvimento de programa de atendimento em saúde mental centrado na reabilitação psicossocial para os hospitais de custódia e tratamento psiquiátrico", as quais não permaneceram na subsequente. Quanto à Política, um diferencial destacado como avanço pelo autor remete à distinção entre a "população penitenciária", constituída de indivíduos julgados e condenados, cumprindo pena em regime fechado (ou internação, no caso de medida de segurança) nos estabelecimentos penais (penitenciárias, hospitais de custódia e tratamento psiquiátrico, presídios e colônias agrícolas ou agroindustriais) e a "carcerária", que engloba as pessoas recolhidas em cadeias públicas e distritos policiais, presos de regime aberto e presos provisórios; sendo que o Plano enfocava exclusivamente a primeira e a Política se estende à população carcerária.

Conclui, então, o tópico ressaltando as negociações para a implantação do Plano e afirmando que sua avaliação, para subsidiar a reformulação de uma política, "deve ser relativizada e contextualizada em relação a outros programas governamentais e outras normativas sobre a saúde no sistema prisional, de modo que seu diferencial - e suas limitações, que persistem - sejam devidamente dimensionados" (p. 36). 
Na parte seguinte, intitulada $A$ gestão, a ponta e um desafio comum: a intersetorialidade, ganham destaque os depoimentos de gestores e profissionais de saúde, muito familiarizados com o cotidiano prisional, que o descreviam por suas vivências, conferindo legitimidade às informaçôes, solicitações e demandas no processo avaliativo. $\mathrm{O}$ autor recomenda que, para além dos comuns espaços de relatos das "experiências exitosas", deveria ter lugar privilegiado a escuta das experiências socioprofissionais cujos dados "não dizem respeito apenas a números de atendimentos, quantidade de recursos financeiros gastos ou inauguração de novas EPENs, mas ao tipo de atenção em saúde que é possível e que tem sido viável sustentar no sistema prisional" (p. 38). Neles é que podem ganhar relevo as dificuldades enfrentadas e os arranjos empreendidos nos Estados e municípios para garantir a saúde dentro do sistema prisional. São arrolados os pontos discutidos para elaboração ou consenso sobre propostas à Política a ser formulada, como se destacam: arranjos para viabilizar e suprir recursos humanos, escolta própria para procedimentos de saúde, montagem e carga horária das equipes; considerar a equidade e equiparar incentivos financeiros aos de outras populações minoritárias (quilombola, indígena, ribeirinha etc.), articulação entre atenção básica e especializada na lógica da RAS.

Um subitem, "A garantia de direitos sociais antes e depois da entrada no sistema prisional", pondera as características de precariedade socioeconômica da maioria da população carcerária brasileira, de modo que significativa parte dela ela ingressa no sistema prisional depois de experiência de vida com poucas oportunidades de estudo, emprego e moradia. Esta particularidade traz desafios à construção da Política em questão porque o esforço em garantir o direito à saúde dar-se-á em meio a privações de direitos civis e políticos, afirma. Neste sentido, perspicazmente, o autor aponta três níveis de análise possíveis: 1) restrição objetiva de acesso (não goza do direito de ir e vir inclusive para procurar serviços de saúde), saída escoltada; 2) o "retributivismo" que remete à "tentativa de sempre agravar a pena para além da privação da liberdade, ${ }^{1}$ mediante a negação de direitos ao preso na execução da pena. Deste nível decorreria a dificuldade de estruturar políticas àqueles em cumprimento de pena, conforme legalmente previstos por compará-los tacitamente aos tantos cidadãos de bem necessitando de ajuda"; 3) ideologia da "periculosidade", que remete aos níveis anteriores, expresso na pouca disposição de esforços para que o preso tenha acesso a saúde, 
educação, já que não seria "merecedor", além de que a oferta plena de direitos nas prisões comprometeria a segurança local.

O autor conta-nos ainda que, no bojo dessas consideraçōes, houve oposições entre agentes penitenciários e de saúde, polarizando o tom das propostas pela visão de "paciente" e "preso", respectivamente, em que "não parece ser apenas a condição objetiva da privação de liberdade que 'explica' essa tensão, mas a própria representação que os agentes de segurança fazem de seu trabalho em função de um conjunto de ideologias sobre crime e criminoso" (grifo no original - p. 44). Somase a esta dificuldade, a questão do "encarceramento em massa", observando que o Brasil é o quarto país neste ranking (precedido por EUA, China e Rússia), sendo que a população prisional em dez anos de implantação do Plano, cresceu mais do que a população brasileira, limitando seu alcance, ainda que tenha avançado muito no credenciamento dos estados e equipes, mas desproporcionalmente à população a atender, ficando a cobertura em torno de $30 \%$.

Consequentemente, há desdobramentos nas condições de estrutura do sistema prisional gerador de insalubridades que comprometem a estratégia atual para a política prisional se não forem observados o deficit de vagas, o tratamento penitenciário, reintegração social e apoio ao egresso, a redução do encarceramento e alternativas penais. As condições insalubres geradoras de agravos e doenças dificulta e/ou impede as ações de prevenção que constam no Plano, sendo apontada a intersetorialidade como forma de enfrentamento da situação. Ignorar a insalubridade, que caminha junto à superlotação, faz com que a Política deixe de ser intersetorial porque não fará frente aos determinantes sociais da saúde, já que as condiçôes do local habitado constituem o principal foco de agravos e doenças.

Diante das sugestões de aplicação das normas da Agência Nacional de Vigilância Sanitária (Anvisa) a toda unidade prisional e não apenas onde a equipe de saúde atua (prevista no Plano), ponderou-se que traria problemas àquele órgão pelas conotações fiscalizadoras mais do que pedagógicas, além dos problemas federativos e entre poderes, já que, a rigor, laudos de insalubridade deveriam gerar o fechamento de unidades prisionais inadequadas. A superlotação e a insalubridade, que se refletem nas dificuldades para higienizar-se e até deitarse/repousar/dormir, tornam problemática a formulação de uma política que aumente o acesso às ações e serviços de saúde, fato exacerbado pelo contexto de 
privação de direitos na história de vida das pessoas privadas de liberdade. Neste sentido, transcrevemos um depoimento muito ilustrativo:

\begin{abstract}
Uma coisa nós temos certeza, né? É que [a falência do sistema prisional] é o significado da falência de tudo lá atrás. Ou seja, a pessoa, ao fazer 18 anos, ela não nasceu criminosa, né? Houve falha na educação, na família, na igreja, na saúde, enfim, todos falhamos [...] é o resultado de muita coisa que incorporou na vida daquele ser humano, daquela pessoa humana que nasceu em condiçōes deploráveis e que o sistema carcerário é tão somente a continuação de tudo que lhe foi negado. (p. 50).
\end{abstract}

Assim, a intersetorialidade, a insalubridade, a superlotação e a privação de direitos das pessoas privadas de liberdade seriam os nós do processo de formulação da Política pretendida, conclui Martinho.

$\mathrm{Na}$ última parte, intitulada $A$ academia, a militância e uma questão semelhante: o monitoramento, ele aponta que nas pesquisas sobre o tema predominam estudos quantitativos sobre condiçôes de saúde, incidência de doenças infectocontagiosas (tuberculose, hepatite, DST e HIV/Aids) e, ainda assim, há carência de pesquisa epidemiológica nacional, que não avançou desde a implantação do Plano. A implantação do prontuário eletrônico é lembrada como possível facilitador de futuros levantamentos sobre a incidência de agravos e doenças. $\mathrm{Na}$ formação de recursos humanos recomenda cuidar em não reproduzir assimetrias, mas considerar a pertinência de agentes de segurança pública serem sensibilizados em relação aos temas de saúde como, igualmente, os profissionais de saúde necessitam de noções de segurança pública e justiça para atuar no sistema prisional. Seriam lógicas distintas (saúde, segurança, justiça), mas que convivem e "precisam ser negociadas no cotidiano carcerário, respeitando as competências exclusivas de cada setor e mantendo uma direção única: a garantia do direito à saúde e proteção dos direitos humanos das pessoas privadas de liberdade" (p. 56).

Atenção especial é dirigida à "Nomeação da população-alvo: penitenciária, carcerária, prisional, privada de liberdade", as quais se referem à situação da pessoa (detida, preso provisório, julgado, cumprindo pena, medida de segurança) e que habitam locais específicos (delegacia, distrito policial, cadeia, centro/casa de detenção, presídio, penitenciária, hospital de custódia e tratamento psiquiátrico). A não inclusão do preso provisório na assistência à saúde pelo Plano justificavase pela falta de espaço físico, mas também isso poderia atrapalhar a assistência jurídica, pois para acelerar o julgamento, defensores alegavam não ser possível 
mais manter o cliente em tão precárias condições. Dessa forma, o Plano atendia aos presos provisórios pela "sorte", isto é, se estivessem em estabelecimento contemplado (pois é comum estarem misturados). Já a Política prevê a ampliação do escopo da população a ser abrangida - a própria comunidade prisional familiares, trabalhadores que lá prestam serviços (da educação, saúde, segurança). Contudo, à tal extensão adianta-se que torna mais difícil rotinizar a prevenção em saúde, o que requer assumir a questão como problema de saúde pública e, portanto, monitorada e efetivando-se o controle social defendido pelo SUS. Somase reconhecer que se trata de uma população em situação de vulnerabilidade e, sendo assim, demanda uma ação focalizada para garantir o direito à saúde.

Nas Consideraçôes Finais, reitera o pesquisador que o Plano (como plano) visava ao modo de fazer /operacionalizar uma política em processo de implementação (no caso a de saúde, pelo SUS) para que também atingisse uma população em situação específica (no caso, a prisional).

O livro traz, ainda, cinco anexos: as 171 propostas registradas pelos grupos de pesquisa durante os grupos de discussão ocorridos nos encontros nacionais com gestores, trabalhadores, pesquisadores e militantes envolvidos no atendimento a pessoas privadas de liberdade no ano de 2012. Ademais, pontua as cinco propostas consensuadas e as cinco rejeitadas; anexa a Portaria Interministerial no 1 , de 02/1/14 (que instituiu a PNAISP no âmbito do SUS), os modelos dos Termos de Adesão do Estado e do município à PNAISP, bem como as diretrizes para o plano de ação estadual/municipal para a PNAISP.

Enfim, a obra, é sensível à questão de uma política que se pauta pelo direito universal à saúde e preconiza equidade, integralidade, acolhimento e humanização postos pelo SUS, traduzindo sua complexidade pela avaliação empreendida e provocando reflexões. Uma delas é que parece que estender a atenção à comunidade prisional decorre do reconhecimento de que a distribuição de presos (condenados, provisórios, em medida de segurança) não se efetiva na prática e que há dificuldade de operacionalizá-la institucionalmente - situação que é cotejada com a prerrogativa de prover a assistência a este contingente. Não se ignora, ademais, a exposição de pessoas de diversos segmentos sociais (familiares, profissionais, religiosos, presos, etc.) devido ao intenso trânsito diário, seja interna (trabalho, visitas) ou externamente (saídas de presos para atendimento jurídico, de saúde, mas também 
pelos alvarás, ingressos, transferências ou trabalho extramuros). Assim, estes também foram incluídos, e esse estatuto pressupõe que estavam excluídos alhures.

Outra reflexão se refere à intervenção em saúde (Plano e Política), que requer ações compartilhadas numa parceria que coloca em interação instituições com histórias, valores e missões distintas gerando tensōes. Tais tensões decorrem, em parte, de contradições nos discursos e práticas das prisões, porque propõem reeducar, ressocializar, regenerar, cuidar e, ao mesmo tempo, historicamente, servem para punir, vigiar, castigar, controlar e disciplinar outros seres humanos (SILVA, 2008; BARCINSKI; ALTENBERND; CAMPANI, 2014). Somamse as perspectivas estigmatizantes da população atendida, que se atualizam e se materializam no cotidiano pelos entraves institucionais da organização dos serviços, sobretudo pelas barreiras de discriminação, por vezes envoltas em nuances tecnicistas e burocráticas, comprometendo assim o direito à saúde (BARSAGLINI; KEHRIG; ARRUDA, 2015).

Destarte, dificuldades decorrem por se voltar a uma população (prisional) que tem aumentado, apresenta um perfil seletivo (MONTEIRO; CARDOSO, 2013), de precariedade e de carências pregressas (em que a prisão funciona como um reforço biográfico) que exacerbam as consequências do ambiente de superlotação e insalubridade, além daquelas decorrentes do confinamento em si. Nesse contexto, é coerente reclamar a focalização de ações e políticas específicas que se mostram compatíveis ou em relação complementar às abrangentes, como recurso para a efetivação da universalidade, mediante promoção da equidade entre grupos em situação desigual (MEDEIROS, 1999; MARSIGLIA; SILVEIRA; CARNEIRO JUNIOR, 2005) e de vulnerabilidade, como se pode entender no caso em tela. Se, dessa forma, a focalização não intimidaria os direitos universais - pelo contrário, reforçá-los-ia, há de ressaltar que, mesmo com as intervençôes focalizadas, persistem dificuldades na garantia social dos direitos já legalmente conquistados da população prisional.

Como ao seu autor, que a leitura nos afete estimulando, reforçando o compromisso e o desafio ético-político da reflexividade e da realização e o uso responsável dos resultados da pesquisa, de modo geral, e da pesquisa avaliativa, em particular, na transformação da realidade da saúde pautada como direito de todo cidadão. 


\section{Referências}

BARCINSKI, M. M. A.; ALTENBERND, B.; CAMPANI, C. C. Entre cuidar e vigiar: ambiguidades e contradiçôes no discurso de uma agente penitenciária. Ciência \& Saúde Col. Rio de Janeiro, v.19, n. 7, p.2245-2254, 2014.

BARSAGLINI, R. A.; KEHRIG, R. T.; ARRUDA, M. B. Análise da percepção de gestores sobre a gestão da política de saúde penitenciária em Mato Grosso. Saúde e Sociedade. São Paulo, v. 24, n. 4, p. 1119-1136, 2015.

BRASIL. Ministério da Saúde. Secretaria de Atenção em Saúde. Departamento de Ações Programáticas Estratégicas. Legislação em saúde no sistema penitenciário. 1a ed. Brasília, DF: SAS, 2010. 172 p. (Série E. Legislação de Saúde).

DUARTE, E. et al. A formação dos gestores municipais de saúde: avaliação de uma experiência. In: DUARTE, E.; BARSAGLINI, R.A. (Orgs.) A Formação dos gestores municipais de saúde: uma experiência político-pedagógica compartilhada. Cuiabá: EdUFMT, 2012. p. 15-88.

GOIS, S.M. et al. Para além das grades e punições: uma revisão sistemática sobre a saúde penitenciária. Ciência \& Saúde Coletiva, Rio de Janeiro, v. 17, n. 5, p. 1235-1246, 2012.

MARSIGLIA, R. M. G.; SILVEIRA, C.; CARNEIRO JUNIOR, N. Políticas sociais: desigualdade, universalidade e focalização na saúde no Brasil. Saúde e Sociedade. São Paulo, v.14, n.2, p. 69-76, 2005.

MARTÍNIC, S. Evaluacion de proyetos: conceptos y herramientas para el aprendizage. México: Comexixani-Cejuv, 1997.

MEDEIROS, M. Princípios de justiça na alocação de recursos em saúde. Brasília: IPEA, 1999.

MONTEIRO, F. M.; CARDOSO, G. R. A seletividade do sistema prisional brasileiro e o perfil da população carcerária. Um debate oportuno. Civitas. Porto Alegre, v. 13, n. 1, p. 93-117, 2013.

PATTON, M. Q. The challenges of making evaluation useful. Ensaio: aval.pol.públ.educ., Rio de Janeiro, v. 13, n. 46, p. 67-78, jan./mar., 2005.

SILVA, A. M. C. Nos braços da lei. O uso da violência negociada no interior das prisões. Rio de Janeiro: E+A, 2008. 170 p.

SILVA, P. L. B.; MELO, M. A. B. O processo de implementação de políticas públicas no Brasil: características e determinantes da avaliação de programas e projetos. Campinas: NEPP/ Unicamp, 2000 (Cad. 48).

\section{Nota}

${ }^{1}$ Em publicação sobre o tema, alertamos para a necessidade de vigiar para que o não cuidado em saúde não venha compor a punição (BARSAGLINI et al., 2015). 